\title{
Training mid-level health cadres to improve health service delivery in rural Bangladesh
}

\author{
Lal B. Rawal ${ }^{1,2}$, Kawkab Mahmud ${ }^{3}$, Sheikh Md. S. Islam ${ }^{4}$, Rashidul A. Mahumud $^{5}$, Md. Nuruzaman $^{6}$ \\ and Syed M. Ahmed ${ }^{7,8}$ \\ ${ }^{1}$ Senior Associate, Research, International Centre for Diarrheal Disease Research, Bangladesh, Dhaka, Bangladesh \\ ${ }^{2}$ Faculty, James P Grant School of Public Health, BRAC University, Dhaka, Bangladesh \\ ${ }^{3}$ Senior Associate, James P Grant School of Public Health, BRAC University, Dhaka, Bangladesh \\ ${ }^{4}$ Senior Research Investigator, International Centre for Diarrheal Disease Research, Bangladesh, Dhaka, Bangladesh \\ ${ }^{5}$ Research Associate, International Centre for Diarrheal Disease Research, Bangladesh, Dhaka, Bangladesh \\ ${ }^{6}$ Research Officer, Human Resources Management Unit, Ministry of Health \& Family Welfare, Dhaka, Bangladesh \\ ${ }^{7}$ Director, CoE-UHC, International Centre for Diarrheal Disease Research, Bangladesh, Dhaka, Bangladesh \\ ${ }^{8}$ Professor, James P Grant School of Public Health, BRAC University, Dhaka, Bangladesh
}

\begin{abstract}
Introduction: In recent years, the government of Bangladesh has encouraged private sector involvement in producing mid-level health cadres including Medical Assistants (MAs). The number of MAs produced has increased significantly. We assessed students' characteristics, educational services, competencies and perceived attitudes towards health service delivery in rural areas. Methods: We used a mixed method approach using quantitative (questionnaire survey) and qualitative (key informant interviews and roundtable discussion) methods. Altogether, five public schools with 238 students and 30 private schools with 732 students were included. Statistical analyses were performed using STATA v-12. Qualitative data were analyzed thematically. Findings: The majority of the students in both public (66\%) and private medical assistant training schools (MATS) (61\%) were from rural backgrounds. They spent the majority of their time in classroom learning (public $45 \%$ versus private $42 \%$ ) and the written essay exam was the common form of a students' performance assessment. Compared with students of public MATS, students of private MATS were more confident in different aspects of educational areas, including managing emerging health needs $(P<0.001)$; evidence-based practice $(P=0.002)$; critical thinking and problem solving $(P=0.02)$, and use of IT/computer skills $(P<0.001)$. Students were aware of not having adequate facilities in rural areas (public $71 \%$, private $65 \%$ ), but they perceived working in rural areas will offer several benefits, including use of learnt skills; friendly rural people; and opportunities for real-life problem solving, etc. Conclusion: This study provides a current picture of MATS students' characteristics, educational services, competencies and perception towards working in rural areas. The MA students in both private and public sectors showed a greater level of willingness to serve in rural health facilities. The results are promising to improve health service delivery, particularly in rural and hard-to-reach areas of Bangladesh.
\end{abstract}

Key words: Bangladesh; health cadres; human resources for health; medical assistant training

Received 14 May 2015; revised 7 February 2016; accepted 4 March 2016;

first published online 31 March 2016

Correspondence to: Lal B. Rawal, Health Systems and Population Studies Division, International Centre for Diarrheal Disease Research, Bangladesh and James P Grant School of Public Health, 68, Shahid Tajuddin Ahmed Sharani, Mohakhali, Dhaka 1212, Bangladesh. Email: dr.lalrawal@gmail.com, lalrawal@icddrb.org

(C) Cambridge University Press 2016

\section{Introduction}

Policy makers around the world, particularly in low-income and middle-income countries (LMICs) are facing significant challenges in meeting the healthcare needs of the general population (World Health 
Organization, 2006; 2007). The main underlying factors are the shortages of qualified health-care providers and the migration (internal/international) of skilled human resources for health $(\mathrm{HRH})$. These factors have a profound impact on the equitable distribution of health-care providers and delivery of quality health services (Dolea et al., 2010; World Health Organization, 2010). Having an adequate number of skilled and motivated health-care providers in LMICs is critically important to deliver health services effectively, and thus to improve population health outcomes (Hongoro and McPake, 2004; World Health Organization, 2010; Anand and Bärnighausen, 2012; Doherty et al., 2013). Shortages of HRH in LMICs like Bangladesh have a significant impact on access to health services and on achieving health and related outcomes (Ahmed et al., 2011; Sustainable Development Goals: Knowledge Platform, 2014).

In recent years, the importance of developing a functional health workforce has been encouraged and been documented extensively (World Health Organization, 2006; Anand and Bärnighausen, 2012; Daniels et al., 2012; Zulu et al., 2013). In the hope of providing a minimum level of health services, World Health Organization (WHO) recommended that the standard density of health-care providers be at least 23 per 10000 population (World Health Organization, 2006). Bangladesh currently does not meet this standard with a ratio of 10 health-care providers per 10000 population (Bangladesh Health Watch, 2007; Ahmed et al., 2011). In addition, there are widespread shortages of key mid-level health cadres, such as Medical Assistants (MAs), Laboratory Technicians, Pharmacists, Radiographers, Physiotherapists, etc. As the majority of the health professionals tend to remain in urban health facilities or at the secondary/tertiary-level health-care facilities, the shortages of health workers is more prevalent in rural and hard-to-reach areas (Bangladesh Health Watch, 2007; Ahmed et al., 2011; Management Information System Directorate General of Health Services Ministry of Health and Family Welfare Bangladesh, 2014). Over 17\% of posts of paraprofessionals are vacant, particularly MAs (22\% vacant), and health-care facilities have higher vacancy rates in rural areas compared with urban areas (Management Information System Directorate General of Health Services Ministry of Health and Family Welfare Bangladesh, 2014).

Given the shortages of skilled HRH, particularly with physicians in the country, producing mid-level health cadres such as MAs has been increasingly important (Bangladesh Health Watch, 2007). In 1979, Bangladesh established public medical assistant training schools (MATS) to provide MAs training and thus produce mid-level health cadres, who would serve in government health facilities at the sub-district and lower level (Bangladesh Health Watch, 2007) and even more recently in community clinics. These health-care facilities are the first point of healthcare in the community and the MAs play significant roles in providing quality primary health-care services (Health Metrics Network Secretariat MoHFW Bangladesh, 2009). In general, MAs assist doctors in clinical and administrative procedures; however, in rural health facilities, they perform these activities independent of a doctors' supervision, as there are widespread shortages of doctors (Osman, 2004; Health Metrics Network Secretariat MoHFW Bangladesh, 2009). The trained MAs are recruited for the position of Sub-Assistant Community Medical Officer at the sub-district and union-level health facilities (Osman, 2004; Management Information System Directorate General of Health Services Ministry of Health and Family Welfare Bangladesh, 2014).

The importance of private sector involvement in producing quality human resources and improving health systems is well documented (Shah et al., 2011). In recent years, many MATS have been established. The production of MAs has significantly increased as a result, with the goal of producing an adequate number of MAs to meet the demand in the health sector and of improving health-care service delivery, specifically in rural areas. However, little information is available regarding these training programmes (International Institute for Educational Planning and UNESCO, 2007; Ministry of Health and Family Welfare Government of Bangladesh, 2011; Human Resource Management Unit Ministry of Health and Family Welfare Bangladesh, 2013). In this study, we assessed students' characteristics, educational services, competencies and perception towards working in rural areas.

\section{Methods}

\section{Study design}

This was a cross-sectional study involving a mixed method approach (qualitative and quantitative). 


\section{Study methods}

In order to gather quantitative data, the final year MATS students completed self-administered survey questionnaires. The data from these questionnaires are primarily presented in this paper (see Table 1 for details). We also conducted two roundtable discussions with key stakeholders to gather their views and opinions towards MATS programmes in Bangladesh. Furthermore, we conducted a thorough review of relevant published and unpublished literature, including reports and policy documents. These findings are also presented here where necessary. In addition, qualitative data were collected through conducting 35 key informant interviews with the institutional heads or representatives of these institutions when the heads were not available. In this paper, only the relevant qualitative information, where necessary, is presented to supplement the quantitative findings.

\section{Sample selection}

We used purposive sampling to determine the institutions, ensuring representation of the institutions by ownership (public or private), geographical representation (rural or urban) and divisional locations (seven administrative divisions in Bangladesh). We selected at least one-third of the existing number of MATS (see Table 1). Selection of at least one private and one public MATS from each division was considered. Given the greater number of MATS in the private sector than the public sector, there is a large difference in the number of private and public institutions selected for this study.
We used a classroom census of the sampled schools to recruit students for the questionnaire survey, specifically final year students. However, for the schools that did not have final year students yet, the groups of students closest to their final year were selected. Table 1 provides a summary of the number of MATS and the sampled students.

\section{Study measurements}

For student-level assessment, a set of selfadministered tools were developed, mainly focussing on assessing students' perception on the training programme, self-competencies, attitudes and perception towards their future career paths. The tools were developed based on the components of WHO health systems building blocks: governance, educational services, financing, health workforce, infrastructure and quality assurance (World Health Organization, 2006).

The study team members developed a set of tools that allowed self-assessment by the students of competencies relevant to different aspects of the MATS programme. In order to maintain internal validity of the study tools, these tools were thoroughly reviewed by the study team members and experts in the MATS programme and were pre-tested before finalization for data collection. The tools assessed the competency level of the students using a rating scale with the levels: 'least confident,' 'neutral' and 'confident'. The results presented below reflect the proportion of the students who responded as confident in their competencies in different aspects of the MATS education.

In addition, study team members developed a set of tools that assessed attitude towards working

Table 1 Sample selection of medical assistant training school and students included in the study

\begin{tabular}{|c|c|c|c|c|c|c|}
\hline \multirow[t]{2}{*}{ Divisions } & \multicolumn{3}{|l|}{ Public } & \multicolumn{3}{|l|}{ Private } \\
\hline & Total schools & Schools selected & Students sampled & Total schools & Schools selected & Students sampled \\
\hline Dhaka & 2 & 2 & 100 & 49 & 14 & 310 \\
\hline Khulna & 3 & 1 & 27 & 6 & 1 & 31 \\
\hline Rajshahi & 1 & 1 & 72 & 24 & 5 & 148 \\
\hline Chittagong & 2 & 1 & 39 & 6 & 2 & 40 \\
\hline Sylhet & - & - & - & 3 & 2 & 58 \\
\hline Rangpur & - & - & - & 10 & 4 & 134 \\
\hline Barisal & - & - & - & 3 & 2 & 11 \\
\hline Total & 8 & 5 & 238 & 101 & 30 & 732 \\
\hline
\end{tabular}


in rural, remote and hard-to-reach areas. In order to maintain internal validity, the study team members and the experts in this area thoroughly reviewed the tools. These tools were then pre-tested before finalization for data collection. The tools assessed attitude of the students using a Likert scale of 'disagree', 'neutral' and 'agree'. The results presented in the table reflect the proportion of the students who described their attitude as 'agree' when asked about willingness to work in rural, remote and hard-to-reach areas in Bangladesh.

Once the entire set of measurement tools were ready, the study team members further thoroughly reviewed the tools in order to ensure the internal validity of the tools. Experts in the areas of health systems, medical education, medical assistant training programmes and community health were requested to conduct a final review. Furthermore, pre-testing of the study tools was conducted in one of the MATS located in Dhaka, Bangladesh. Before finalizing the tools, these were further revised and amended based on the results obtained from the pre-testing.

The key informant interview guidelines to collect institutional-level data were developed and used in the sampled MATS. The guidelines were also developed mainly based on the WHO health systems building blocks, primarily focussed on governance, health workforce and financing. (World Health Organization, 2006). Additional relevant components added included educational services, infrastructure and quality assurance. The guidelines were reviewed by the study team members multiple times before being sent to the relevant experts for further review. Following their comments, these tools were pre-tested in one of the MATS nearby Dhaka and necessary revisions were made accordingly, before administering the tools to the sampled MATS throughout the country.

\section{Field data collection}

A group comprised of trained research assistants and a research officer collected data during the months of February and June 2013 under the close supervision of the project team coordinators.

\section{Data analysis}

Quantitative data were entered into the SPSS version 17.0 and was cleaned before performing preliminary analysis. The cleaned data were then transferred into STATA version-12 for all further necessary analyses. Summary statistics describing students' characteristics, educational services, competencies and perception towards health service delivery in rural areas are presented by mean, median, number and percentages. Univariate comparison between public and private MATS students uses Pearson's $\chi^{2}$ test for categorical variables and either two independent sample $t$-test or Mann-Whitney $U$ test for continuous variables as appropriate.

Upon completion of qualitative data collection, we compiled and read all transcripts for data familiarization. General codes were identified from transcripts and categorized into sub-groups, such as governance, educational services, health workforce, financing and quality of education. Main themes and sub-themes emerging from interviews and document review were identified. These patterns were analysed and an effort was made to triangulate these findings with the findings obtained from the quantitative study.

\section{Ethics approval}

Ethics approval of this study was obtained from the Bangladesh Medical Research Council. This is a national body looking after the ethical aspects of health research in Bangladesh. Before the survey and interviews, the participants were fully informed about the objective of the study and the data collection process. Informed verbal consent was obtained before all the surveys and interviews and also for the tape recording of the interviews. Approval from the sampled MAT school also was obtained before the data collection. Anonymity of the questionnaire responses and interviews was maintained to ensure confidentiality of the information. The participants were given full assurance that they had the right to participate or not to participate in the study or terminate their participation anytime without any explanation.

\section{Results}

\section{General characteristics of the students}

As shown in Table 2, the majority of the students were male $(58.87 \%)$, mean age $18.53(\mathrm{SD} \pm 1.27)$ and most of them graduated from a rural high school $(62.16 \%)$. Almost two-thirds of students' fathers 
Table 2 General characteristics of the medical assistant training school students

\begin{tabular}{|c|c|c|c|c|}
\hline General characteristics & Public & Private & Total & $P$-value \\
\hline Age $($ mean $\pm S D)$ & $18.8 \pm 0.96$ & $18.5 \pm 1.34$ & $18.5 \pm 1.27$ & 0.001 \\
\hline \multicolumn{5}{|l|}{ Sex } \\
\hline Male & $58.4(139)$ & $59.0(432)$ & $58.98(571)$ & \multirow[t]{2}{*}{0.867} \\
\hline Female & $41.6(99)$ & $41.0(300)$ & $41.1(399)$ & \\
\hline \multicolumn{5}{|l|}{ Location of high school } \\
\hline Rural & $66.0(157)$ & $60.9(446)$ & $62.2(603)$ & \multirow[t]{2}{*}{0.077} \\
\hline Urban & $34.0(81)$ & $39.1(286)$ & $37.8(367)$ & \\
\hline \multicolumn{5}{|l|}{ Fathers' occupation } \\
\hline Formal sector (government/private, business) & $66.0(157)$ & $60.9(446)$ & $62.2(603)$ & \multirow[t]{2}{*}{0.548} \\
\hline Informal sector & $34.0(81)$ & $39.1(286)$ & $37.8(367)$ & \\
\hline \multicolumn{5}{|l|}{ Mothers' occupation } \\
\hline Formal sector & $7.6(18)$ & $7.8(57)$ & $7.7(75)$ & \multirow[t]{2}{*}{0.953} \\
\hline Informal sector & $92.4(220)$ & $92.2(675)$ & $92.3(895)$ & \\
\hline \multicolumn{5}{|l|}{ Father's education level } \\
\hline Never attended & $10.5(25)$ & $4.0(29)$ & $5.6(54)$ & \multirow[t]{5}{*}{0.016} \\
\hline Primary level & $21.4(51)$ & $19.1(140)$ & $19.7(191)$ & \\
\hline Secondary and higher secondary level & $48.3(115)$ & 54.5 (399) & $52.99(514)$ & \\
\hline Diploma and vocational level & $1.7(4)$ & $4.5(33)$ & $3.8(37)$ & \\
\hline Bachelor and higher level & $18.1(43)$ & $17.5(128)$ & $17.6(171)$ & \\
\hline \multicolumn{5}{|l|}{ Mother's education level } \\
\hline Never attended & $13.0(31)$ & $5.1(37)$ & $7.0(68)$ & \multirow[t]{5}{*}{0.003} \\
\hline Primary level & $32.4(77)$ & $31.7(232)$ & $31.9(309)$ & \\
\hline Secondary and higher secondary level & $49.6(118)$ & $78.3(425)$ & $100(543)$ & \\
\hline Diploma and vocational level & $1.3(3)$ & $1.0(7)$ & $1.0(10)$ & \\
\hline Bachelor and higher level & $3.8(9)$ & $4.2(31)$ & $4.1(40)$ & \\
\hline
\end{tabular}

worked in the formal sector $(62.16 \%)$, including occupations in the government/private sector and business, whereas almost all mothers $(92.27 \%)$ were involved in the informal sector, as housewife and farmer.

\section{Educational services}

The number of students getting into MATS has increased over the past 10 years, particularly after the private sector became involved in 2008. For public MATS, most students are admitted through the national exam conducted by the Medical Faculty Board, whereas in the private sector, students are admitted through an institutional exam, conducted by the respective MATS (Figure 1).

Most of the key informants interviewed responded in a similar way to one respondent commenting that:

'the MATS program in Bangladesh is well standardized, includes medical and general education, and covers almost all aspects of medical assistant training that enhance their competency in general subjects and technical subjects, in addition to a 12 months internship at the district hospital (9 months) and at the upazila (sub-district) level health complex (3 months)'. (KII 3 (private)_MATS)

However, a few key informants shared the opinion that the curriculum covers all aspects of medical education like MBBS course, but the duration is not enough to cover all contents included in the curriculum. In addition, there is a lack of number of quality course books as recommended in the curriculum' (KIIs 3, 4 and 8 (private) and KII 4 (public)_MATS).

A key informant institutional head stated that 'there is no specific mechanism to review the MATS curriculum and it is in general based on needs of the time. The Centre for Medical Education normally takes the lead for this, so far we have not revised the curriculum...'(KII 12 (private)_MATS).

Regarding the medium of teaching, learning and evaluation, a few key informants mentioned that in general, English is used in the textbooks; however, some books are available in the local language (Bangali) as well. Teachers generally use a mix of English and Bengali languages in the classroom and 


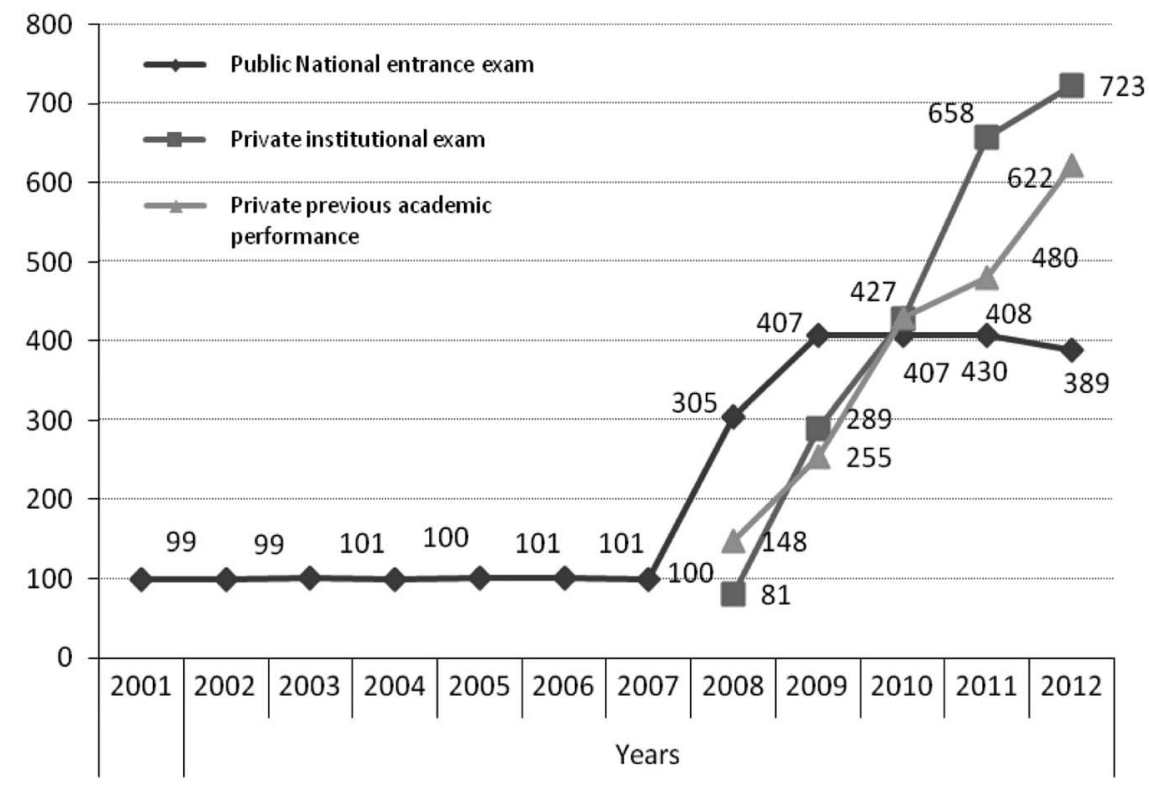

Figure 1 Number of students entered into medical assistant training school programme through different criteria in past 10 years

the examinations are held in English' (KIIs 3, 4 and 8 (private) and KII 5 (public)_MATS).

The timely completion rate of those students who entered into the MATS in 2008 was similar in both private and public schools; however, the delayed completion rate was higher in private MATS compared with public MATS. Similarly, the dropout rate was higher in private schools than in public schools, which may be due to the higher tuition fees charged in private MATS compared with public MATS or other factors. However, the percentage of students whose information was not available was higher in public $(20 \%)$ than the private MATS $(2 \%)$. This discrepancy may be due to a number of possibilities such as: many students in the public sector may have dropped out but the records were not kept up to date; the students may have been waiting to graduate and the records were not available; the students may have completed their study, but the records may not have kept up to date. These possibilities may need further exploration. (Figure 2).

\section{Competency self-assessment}

As shown in Table 3, the self-assessed competency in different aspects of MATs curriculum was higher among the private MAT students compared with the students from the public MATS. These differences were statistically significant and include health promotion and prevention $(P<0.001)$; managing emerging health needs $(P<0.001)$, evidence-based practice $(P=0.002)$, critical thinking and problemsolving skills $(P=0.02)$ and managing population health $(P=0.03)$. Furthermore, a significant difference was found for other competencies, including leadership and participation $(P=0.001)$, cultural competency in healthcare $(P=0.004)$, IT and computer skills $(P<0.001)$ and continuing lifelong learning $(P=0.003)$ (Table 3).

\section{Perception towards working in rural, remote or hard-to-reach areas and job preference}

Table 4 suggests that the majority of the students knew that the rural and hard-to-reach areas do not have adequate amenities and entertainment facilities (reflected in proportions of public $71 \%$ and private $65 \%, P<0.08)$. However, the students believed that working in these areas can have other benefits, such as opportunities to work independently, utilizing various skills learned in school, people being friendly, opportunities for real-life problem solving and the programme being helpful in preparing students to work in rural/remote areas. 


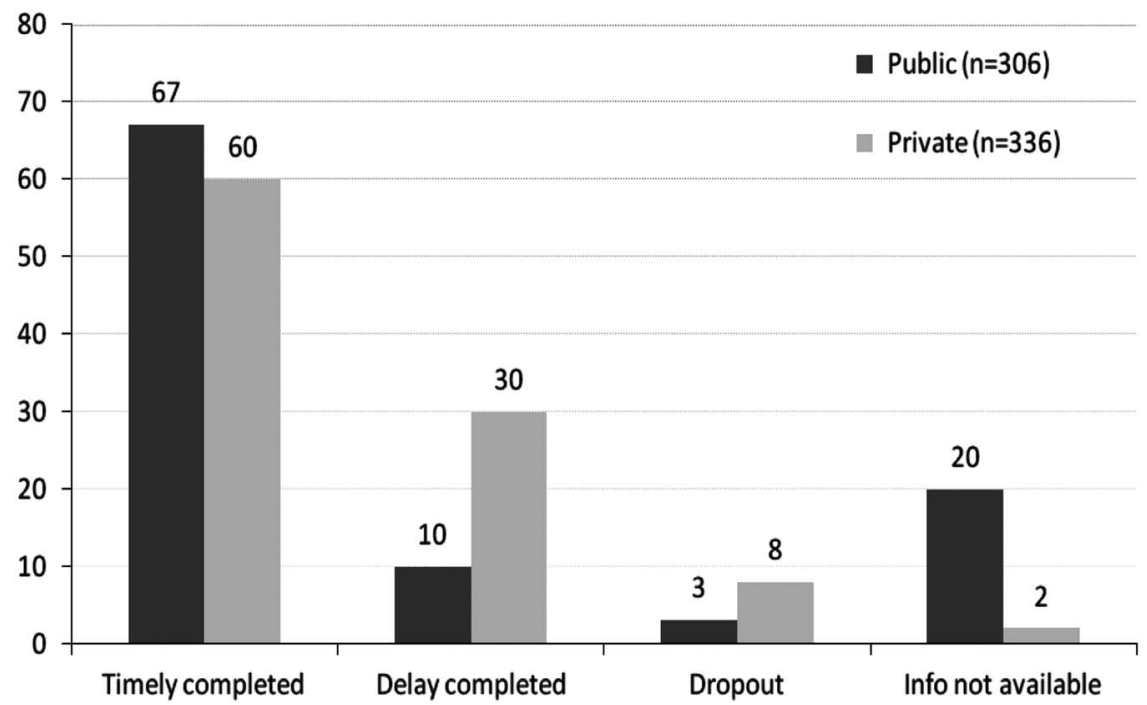

Figure 2 Percentage graduated/dropped out of those students who entered into the medical assistant training school in 2008

Table 3 Competency self-assessment

\begin{tabular}{|c|c|c|c|c|}
\hline Confident in & Private $\%(n=732)$ & Public $\%(n=238)$ & $\%$ Difference $(95 \% \mathrm{Cl})$ & $P$-value \\
\hline Professional judgement, ethical standard & $93.2(682)$ & $89.1(212)$ & $4(-0.3,8)$ & 0.048 \\
\hline Provision of MAT care & $93.4(684)$ & $88.2(210)$ & $5(0.5,10)$ & 0.015 \\
\hline Health promotion/prevention & $91.7(671)$ & $76.9(183)$ & $15(9,21)$ & $<0.001$ \\
\hline Emerging health needs & $63.1(462)$ & $31.1(74)$ & $32(25,39)$ & $<0.001$ \\
\hline Evidence-based practice & $82.5(604)$ & $73.9(176)$ & $9(3,15)$ & 0.002 \\
\hline Critical thinking and problem solving & $72.7(532)$ & $64.7(154)$ & $8(1,15)$ & 0.018 \\
\hline Partnership with communities & $81.3(595)$ & $76.1(181)$ & $5(-1,11)$ & 0.095 \\
\hline Managing population health & $83.7(613)$ & $78.2(186)$ & $6(0.1,12)$ & 0.0342 \\
\hline Collaborate team & $91.5(670)$ & $91.2(217)$ & $1(-3,5)$ & 0.626 \\
\hline Leadership and participation & $77.9(570)$ & 64.7 (154) & $13(6,20)$ & $<0.001$ \\
\hline Promoting a safe work place & $82(600)$ & $79.4(189)$ & $3(-3,9)$ & 0.303 \\
\hline Cultural competency in healthcare & $82.8(606)$ & $76.9(183)$ & $6(0,12)$ & 0.038 \\
\hline Information technology and computer skills & $72.4(530)$ & $52.9(126)$ & $19(12,26)$ & $<0.001$ \\
\hline Continuing lifelong learning & $87.3(639)$ & $79.4(189)$ & $8(2,14)$ & 0.003 \\
\hline Overall perceived competency & $82.9(607)$ & $72.7(173)$ & $10(4,16)$ & 0.001 \\
\hline
\end{tabular}

$\mathrm{MAT}=$ medical assistant training.

Students from both sectors perceived that working in rural areas has many challenges and also can lack a supportive working environment. Overall, the perception towards working in rural areas was not significantly different between the students of public and private MATS programme (Table 4).

After graduating, the majority of the MATS students from both sectors (public $76 \%$, private
$70 \%$ ) preferred to work in the health services run by the public sector in the country. Obtaining good welfare, developing good career prospects and also living closer to their communities were some of the major reasons of why students wanted to work in the public sector health services. However, they did not prioritize making money in deciding their job preferences. 
Table 4 Perceived attitude towards rural, remote or hardship areas

\begin{tabular}{|c|c|c|c|c|}
\hline Perceived attitude & $\begin{array}{l}\text { Private \% } \\
(n=732)\end{array}$ & $\begin{array}{l}\text { Public \% } \\
(n=238)\end{array}$ & $\begin{array}{l}\text { \% Difference } \\
(95 \% \mathrm{Cl})\end{array}$ & $P$-value \\
\hline Opportunities to use various skills & $69.7(510)$ & $63.0(150)$ & $6(-1,13)$ & 0.086 \\
\hline Supportive environment & $40.6(297)$ & $10.1(24)$ & $30(25,35)$ & $<0.001$ \\
\hline Limits professional communication & $38.4(281)$ & $46.6(111)$ & $-9(-16,-2)$ & 0.014 \\
\hline Opportunities to work independently & $55.7(408)$ & $44.5(106)$ & $12(5,19)$ & 0.001 \\
\hline Lack of amenities and entertainment & $65.2(477)$ & $70.6(168)$ & $-6(-13,0.7)$ & 0.089 \\
\hline Rural people are friendly & $74.9(548)$ & $71.4(170)$ & $4(-3,11)$ & 0.222 \\
\hline Results in isolation from friends/family & $42.9(314)$ & $45.0(107)$ & $-2(-9,5)$ & 0.589 \\
\hline Contribution to population health & $96.0(703)$ & $94.1(224)$ & $2(-1,5)$ & 0.196 \\
\hline MATS helped me to work in these areas & $87.0(637)$ & $84.5(201)$ & $3(-2,8)$ & 0.243 \\
\hline MATS inspired me to work in hospitals in rural areas & $87.3(639)$ & $87.8(209)$ & $-1(-6,4)$ & 0.688 \\
\hline Abundant amenities and entertainment & $15.7(115)$ & $10.0(24)$ & $6(1,11)$ & 0.023 \\
\hline Working these areas is most challenging & $28.3(207)$ & $31.1(74)$ & $-3(-10,4)$ & 0.374 \\
\hline Opportunities for real-life problem solving & $73.1(535)$ & $67.6(161)$ & $5(-2,12)$ & 0.137 \\
\hline Overall perception & $60.0(439)$ & $55.9(133)$ & $4(-3,11)$ & 0.256 \\
\hline
\end{tabular}

MATS $=$ medical assistant training school.

\section{Discussion}

A shortage of medical doctors is one of the major health systems challenges in LMICs, including Bangladesh, particularly in rural settings (Bangladesh Health Watch, 2007). By producing a health worker who would be specifically appointed to rural areas, where the retention of doctors has been a chronic problem, the MATS programme in Bangladesh has attempted to address the HRH crisis in the country. This effort has fostered improving skill mix balance and combating ruralurban mal-distribution. Training mid-level health cadres and task-shifting has been considered an effective approach to overcome health workforce shortages in LMICs (Fulton et al., 2011). These qualified MAs in Bangladesh have a huge potential for providing a growing proportion of health services to the rural population.

The results from this study provided a description of the current status of MATS students' characteristics, educational services, competencies and perception towards working in rural areas. Results suggest that the self-assessed perceived competency in most key aspects of MA training were significantly higher among the students of private MATS compared with public MATS, including managing emerging health needs $(P<0.001)$, evidence-based practice $(P=0.002)$, critical thinking and problem-solving skills $(P=0.02)$. High levels of competency are critically important in terms of academic achievement as well as building the confidence in providing quality of care. A study by Achembong et al. (2012) in Cameron suggested that the mid-level health cadres, particularly in dental care, were able to enhance their capacity through the training for quality dental care and discharge the services accordingly. They were also confident enough to provide dental services independently in the clinics located in rural areas (Achembong et al., 2012). This study also identified that the services provided by the mid-level health cadres such as dental assistants were low-cost and easily accessible in the rural areas.

The currently available evidence suggests that, where the mid-level health cadres are adequately trained and well supported by health systems, there is potential to improve the distribution of health workers, particularly in rural areas where the physicians, in most cases, would be reluctant to be located (Pereira et al., 2007; Pallas et al., 2013; Doherty et al., 2013). The training of the mid-level health workers would also increase the equitable access to health services, while retaining, if not exceeding, the quality of care provided by physicians (Brown et al., 2011). A study by Pereira et al. (2007) suggested that the mid-level health cadres such as 'técnicos decirurgia' in Mozambique had a retention rate as high as $88 \%$ in district-level health facilities even after seven years of posting, compared with zero for the posted medical doctors (Pereira et al., 2007). 
Our study findings suggest that the students spent the majority of their time in the classroom and with a traditional lecture-based method as a main mode of instruction. These findings are similar to those identified in other health and related courses including medical, nursing and public health (James P Grant School of Public Health, BRAC University and RTM International, 2014). There is a strong evidence base for changing teaching and learning methodologies to focus on problem-based learning (Frenk et al., 2010), which would help students enhance the core competencies of the training. Furthermore, an increased duration for the community practicum is also necessary to have a better understanding about the health problems faced by people in their communities and the community-based approaches that would be required to alleviate these problems.

The findings also suggest that the majority of the students were aware of not having adequate facilities in rural areas $(P=0.002)$, but they perceived that working in rural areas will offer several other benefits, such as the use of skills they have learnt, friendly rural people and opportunities for real-life problem solving, etc. A method of recruiting the students using a district quota system has played a significant role in encouraging the rural students to enter into the programme. Thus, we found that the majority of the students $(60 \%)$ came from a rural background, and in general their intention towards taking up jobs in rural areas was quite positive. Evidence from other countries also suggests that training students with rural backgrounds increases the likelihood of taking rural jobs after the graduation (Laven and Wilkinson, 2003; Woloschuk and Tarrant, 2004; Wilson et al., 2009; Walker et al., 2012; Rawal et al., 2015). In the case of medical doctors, a systematic review showed that doctors with a rural background are twice as likely to work as rural doctors compared with those with an urban background (Laven and Wilkinson, 2003). Studies in Australia (Walker et al., 2012) and South Africa (Vries and Reid, 2003) suggested that doctors with a rural background were up to 10 times as likely to prefer rural jobs compared with doctors from other backgrounds (Vries and Reid, 2003).

The services provided by the MAs, particularly in rural areas of Bangladesh have contributed significantly to the delivery of preventive and curative services at community level. However, further studies are needed to examine how the quality of care has been impacted (Management Information System Directorate General of Health Services Ministry of Health and Family Welfare Bangladesh, 2014). As shown in this study, currently a huge number of private schools are adding substantially to the pool of MAs of the country. This boom has definitely improved the access of health services, particularly in the rural areas. However, the questions remain about the quality of the training and the services provided by these trained MAs (Ministry of Health and Family Welfare Government of Bangladesh, 2011). Perhaps, there is a need for further research to investigate the quality of the training provided in these institutions as well as of services eventually provided by those trained in these institutions.

Limitations of this study include a variation in the sample size of private and public MATS. This is due to the greater number of MATS in the private sector compared with the public sector, resulting in a large difference in the number of private and public institutions selected for this study. Another limitation includes the lack of detail on the qualitative findings in this manuscript. Further details on qualitative findings are planned for a future manuscript. Furthermore, the quantitative findings such as competencies and attitudes were assessed using self-reported questionnaire, which do not necessarily reflect on objective assessment, meaning that the outcomes and the findings of this study should be interpreted with reasonable caution.

\section{Conclusion}

This study provides a description of the current situation of the MATS programme in Bangladesh, specifically focussed on MATS students' characteristics, educational services, competencies and perception towards working in rural areas. The MATS students in both private and public sector showed a willingness to serve in rural health facilities. Thus, this provides considerable potential in maximizing the presence of these trained mid-level health cadres in health facilities located in rural and hard-to-reach areas and to improve health service delivery in these facilities.

Although the private sector is playing crucial roles in producing an adequate number of competent MAs to serve the increasing demand of the country, there is a need for formulating 
a comprehensive strategic plan to address all possible aspects of training mid-level health cadres including MAs.

\section{Acknowledgements}

The authors gratefully acknowledge the financial and technical support provided by WHO Bangladesh under the BAN HRH programme, and the collaboration received from HRM Unit Ministry of Health and Family Welfare; Directorate General of Health Services and James P Grant School of Public Health, BRAC University. The authors thank Dr Tim Evans, currently with the World Bank, for his overall guidance to the study. They also thank Lindsey Hiebert and Sequoia Leuba for critically reviewing the manuscript and for their constructive comments and feedback. The authors also acknowledge the International Centre for Diarrheal Disease Research, Bangladesh core donors including Australia DFAT, Canadian CIDA, Swedish SIDA, UK DFID and the government of Bangladesh.

Authors' contribution: L.B.R., K.M. and N.Z. contributed to designing and drafting the manuscript (all sections). L.B.R. and R.A.M. further contributed in analyzing the data. S.M.S.I. and S.M.A. revised the manuscript critically. All authors approved the final version of the manuscript.

\section{Conflicts of Interest}

None.

\section{References}

Achembong, L., Ashu, A., Hagopian, A., Downer, A. and Barnhart, S. 2012: Cameroon mid-level providers offer a promising public health dentistry model. Human Resources for Health 10, 46.

Ahmed, S.M., Hossain, M.A., Raja Chowdhury, A. and Bhuiya, A. 2011: The health workforce crisis in Bangladesh: shortage, inappropriate skill-mix and inequitable distribution. Human Resources for Health 9, 3.

Anand, S. and Bärnighausen, T. 2012: Health workers at the core of the health system: framework and research issues. Health Policy 105, 185-91.

Bangladesh Health Watch. 2007. The state of health in Bangladesh 2007: health workforce in Bangladesh. Dhaka: James P Grant School of Public Health, BRAC University.

Primary Health Care Research \& Development 2016; 17: 503-513
Brown, A., Cometto, G., Cumbi, A., de Pinho, H., Kamwendo, F., Lehmann, U. and Sanders, D. 2011: Trabajadores de salud de nivel intermedio: un recurso prometedor. Revista Peruana de Medicina Experimental y Salud Pública 28, 308-15.

Daniels, K., Clarke, M. and Ringsberg, K. 2012: Developing lay health worker policy in South Africa: a qualitative study. Health Research Policy and Systems 10, 8.

Doherty, J., Conco, D., Couper, I. and Fonn, S. 2013: Developing a new mid-level health worker: lessons from South Africa's experience with clinical associates. Global Health Action 6, 10.

Dolea, C., Stormont, L. and Braichet, J.M. 2010: Evaluated strategies to increase attraction and retention of health workers in remote and rural areas. Bulletin of the World Health Organization 88, 379-85.

Frenk, J., Chen, L., Bhutta, Z.A., Cohen, J., Crisp, N., Evans, T., Fineberg, H., Garcia, P., Ke, Y., Kelley, P., Kistnasamy, B., Meleis, A., Naylor, D., Pablos-Mendez, A., Reddy, S., Scrimshaw, S., Sepulveda, J., da, D.S. and Zurayk, H. 2010: Health professionals for a new century: transforming education to strengthen health systems in an interdependent world. The Lancet 376, 1923-958.

Fulton, B., Scheffler, R., Sparkes, S., Auh, E., Vujicic, M. and Soucat, A. 2011: Health workforce skill mix and task shifting in low income countries: a review of recent evidence. Human Resources for Health 9, 1.

Health Metrics Network Secretariat MoHFW Bangladesh. 2009: Health information system assessment: Bangladesh country report. Ministry of Health and Family Welfare (MoHFW), Government of Bangladesh, Dhaka, Bangladesh.

Hongoro, C. and McPake, B. 2004: How to bridge the gap in human resources for health. The Lancet 364, 1451-456.

Human Resource Management Unit Ministry of Health and Family Welfare Bangladesh. 2013. Human resources for health country profile Bangladesh. Dhaka: MoHFW.

International Institute for Educational Planning and UNESCO. 2007. Private higher education in Bangladesh. Paris, France: International Institute for Educational Planning and UNESCO.

James P Grant School of Public Health, BRAC University and RTM International. 2014. Health professional education of Bangladesh: a situation analyses. Dhaka: James P Grant School of Public Health.

Laven, G. and Wilkinson, D. 2003: Rural doctors and rural backgrounds: how strong is the evidence? A systematic review. Australian Journal of Rural Health 11, 277-84.

Management Information System Directorate General of Health Services Ministry of Health and Family Welfare Bangladesh. 2014. Health bulletin 2014. Dhaka: Ministry of Health and Family Welfare, Government of People's Republic of Bangladesh.

Ministry of Health and Family Welfare Government of Bangladesh. 2011: National health policy 2011. Dhaka, Bangladesh: MoHFW.

Osman, F.A. 2004. Policy making in Bangladesh: a study of the health policy process. Dhaka, Bangladesh: A.H. Development Publishing House. 
Pallas, S.W., Minhas, D., Pérez-Escamilla, R., Taylor, L., Curry, L. and Bradley, E.H. 2013: Community health workers in low- and middle-income countries: what do we know about scaling up and sustainability? American Journal of Public Health 103, e74-82.

Pereira, C., Cumbi, A., Malalane, R., Vaz, F., McCord, C., Bacci, A. and Bergström, S. 2007: Meeting the need for emergency obstetric care in Mozambique: work performance and histories of medical doctors and assistant medical officers trained for surgery. BJOG: An International Journal of Obstetrics \& Gynaecology 114, 1530-533.

Rawal, L.B., Joarder, T., Islam, S.M.S., Uddin, A. and Ahmed, S.M. 2015. Developing effective policy strategies to retain health workers in rural Bangladesh: a policy analysis. Dhaka: Human Resources for Health. 13, 36.

Shah, N.M., Brieger, W.R. and Peters, D.H. 2011: Can interventions improve health services from informal private providers in low and middle-income countries? A comprehensive review of the literature. Health Policy and Planning 26, 275-87.

Sustainable Development Goals: Knowledge Platform. 2014: Sustainable development goals: open working group proposal for sustainable development goals. Retrieved 16 November 2014 from http://sustainabledevelopment.un. org/sdgsproposal.html.

Vries, E.D. and Reid, S. 2003: Do South African medical students of rural origin return to rural practice? South African Medical Journal 93, 789-93.
Walker, J.H., Dewitt, D.E., Pallant, J.F. and Cunningham, C.E. 2012: Rural origin plus a rural clinical school placement is a significant predictor of medical students' intentions to practice rurally: a multi-university study. Rural and Remote Health (Online) 12, 1908.

Wilson, N.W., Couper, I.D., De Vries, E., Reid, S., Fish, T. and Marais, B.J. 2009: A critical review of interventions to redress the inequitable distribution of healthcare professionals to rural and remote areas. Rural and Remote Health (Online) 9, 1060.

Woloschuk, W. and Tarrant, M. 2004: Do students from rural backgrounds engage in rural family practice more than their urban-raised peers? Medical Education 38, 259-61.

World Health Organization. 2006. Working together for health; the world health report 2006. Geneva: World Health Organization.

World Health Organization. 2007. Everybody business: strengthening health systems to improve health outcomes: WHO's framework for action. Geneva: World Health Organization.

World Health Organization. 2010. Global policy recommendations - increasing access to health workers in remote and rural areas through improved retention. Geneva: World Health Organization, 1-72.

Zulu, J., Kinsman, J., Michelo, C. and Hurtig, A.K. 2013: Developing the national community health assistant strategy in Zambia: a policy analysis. Health Research Policy and Systems 11, 24. 